from the disease at school on the afternoon of March 2nd. For some months previous to this no cases had occurred in this neighbourhood, and the school had always remained very free from diseases of an infectious nature. Inclusive of the above case, $3 l$ notifisations were received between March $6 \mathrm{th}$ and $18^{\mathrm{t}} \mathrm{h}$, and 13 deaths resulted, a percentage of nearly 43. The ficst case which was the cause of the outbreak proved fatal, and of the 11 casea primarily infected by this 7 died. In 7 cases the first symptoms appeared on the evening of March $4 \mathrm{bh}$, and of tho-e 6 died; in 4 on March 5 th, with 1 death; and in 4 on March 6 th, with 1 death. These 15 çses were all infected at school on March 2nd, 3rd, and 4th, and, as might have been anticipated, were the cause of other cases, not only in the same households, but in others. One monitor, a girl aged fourteen years, was infected on March 5th as on that date in school she nursed one of the previnusly infected cases who had turned ill, and the first sympt ims appeared on March $8 \mathrm{ih}$. The type of disease in the early cases was more virulent, but the secondary and tertiary cases were of a mild $t_{r}$ type. In all, twenty-five households were infected, but owing to prompt diagnosis, notification, and isolation the outbreak did not last long. The disease was so virulent and the symptoms in the early stages were so definite that prompt isolation was at once carried out, with the result that in these households only two had secondary or tertiary cases. The schonl was closed on March $8 \mathrm{th}$ for twenty-one days, and after that date thirteen cases were notified, but of these four caies occurred in households previously infected. An analysis of the other nine cases showed that two in whom the first symptoms appeared on March 9 th had been at school on the $5 \mathrm{sh}$ and $8 \mathrm{th}$, while the remaining seven were all ascertzined to have come into dicect contact with some of the previously notified cases. The last notification from this part of the district was received on March $22 \mathrm{ad}$, the first symptoms having appeared on the $20 \mathrm{th}$, and the outbreak subsided almost as rapidly as it had commenced. In nine of the houses where cases occurred sanitary defects were found after testing, but these, as in the ontbreak in Ward 1, were of a slight character, mainly consisting of defective watercloset arrangements. In all the cases occurring in these houses a definite history of contact with a previous case was obtained. The milk-supply in all cases was the subject of careful inquiry, but no connexion between this and the outbreaks in either ward conld be traced. The sanitary arrangements of the school in Ward 1 were carefully examined and the drains tested, but only a slight defect was found, this consisting of an untrapped rain-water pipe. In Ward 3 the sanitary arrangements of the school were excellent, the drains having only recently been laid under the supervision of the sanitary inspector.

A review of all the circamstances attending the three outbreaks-the one at Roehampton and the two in Wandsworth-emphasises the fact that diphtheria may show varying degrees of virnlence in different outbreaks. In the Roehampton outbreak out of 30 cases reported not one proved fatal. In the first outbreak in this parish 45 cases were reported, of which 12 proved fatal, and in the second 31 cases with 13 deaths. Again, in Ward 1 of this parish diphtheria had been present, though in a mild form, during the previous year ; and it is a well-known fact that virulent outbreaks are frequently preceded by a prevalence of sore-throat or of true diphtheria of a mild character. It is difficult to say definitely whether the outbreak in Ward 3 arose out of that in Ward 1. Every inquiry was made into the history of the child first affected in Ward 3 , but no definite information could be obtained as to contact with any of the cases in Ward 1. It is quite within the bounds of possibility that such contact did take place, and if so it would further verify the statement made by Sir R. Thorne Thorne as to the progressive power of infectiveness of this disease. The lessons to be drawn from these and similar outbreaks are, in my opinion-that all cases of sore throat should be immediately isolated, and that when possible a bacteriological examination should be made. Immediate notification should be made to the medical officer of health, not only of cases where the symptoms are on the first examination definite, but also in all cases which are at all suspicious. These measures would ensure the exclusion of all infected children from school, and this is, in my opinion, the most important etiological factor in the dissemination of diphtheria in urban localities, and especially in the metropolis.

Wandsworth, S.W

\section{A CASE OF APPENDICITIS WITH SOME: UNUSUAL SYMPTOMS.}

\section{By CHARLES D. GREEN, M.D. LOND., F.R.C.S. ENG.}

AN ill-nourished and unōersized lad, aged fifteen years, was on Sept. 27th, 1893, while employed in field work, obliged to return home on account of abdominal pain. I saw him the same evening; he gave no history of any pre. vious bowel trouble. He had felt a little pain in the abdomen before starting for work, but went to work as usual, walking nearly two miles for the purpose. He continued at work during the morning, but was obliged to return early in the afternoon on account of increase in the pain. He had vomited once during the day. When I saw him he was lying on his back; he did not appear to be seriously ill; his abdomen was not distended, and no tenderness was elicitea on examination; his tongue was clean and moist, and his bowels had been open. He had eaten some raw turnip, amongst otber things, during the day; no aperient was given, but absolute rest was enjoined. The next day some tenderness was evident in the right iliac fossa. On the 29th the temperature was $101^{\circ} \mathrm{F}$.; there was some exadation on the right side; the abdominal walls were rigid; there was a distinct tender spot two inches below, and one inch external to, the umbilicus, and at this spot there seemed to be a greater sense of resistance than elsewhere. The sense of resistance was, however, ill.defined and diffuse; there was no dulness on percussion. The next day (the 30th) the temperature was $102^{\circ}$ and there was a little dulness over the tender spot; the general condition did not seem grave. On Oct. 1st and 2nd there appeared to be some amelioration; the temperature on the latter date was $100^{\circ}$, the tongue was moist and clean, there had been no further vomiting since the onset, and the general condition remained about the same; the signs of local exudation were more distinct. So far the case had appeared to me to have been a simple one of appendicitis, localised and threatening to suppurate, but not. calling for immediate operation. On the night of the $2 \mathrm{nd}$, however, a sudden and severe exacerbation of pain took place. On the 3 rd the temperature was $101^{\circ}$, there was considerable distension of the abdomen, and severe pain referred to the right iliac region; the dulness previously noticed had disappeared. On very light percussion, however, the note seemed somewhat damped over a small area the centre of which was about the middle of a line drawn from the umbilicus to the middle of the right Poupart's ligament. There had been no vomiting. The treatment had hitherto been small doses of opinm and enemata; these latter had, however, only brought away a small quantity of hard faces, evidently from the lower bowel, and it was stated that no flatus had been passed. It was now evident that operation was called for, and it seemed to me that perforation of the appendix had taken place during the night and that if general peritonitis had not already begun the risk of its occurrence would be materially increased by moving the patient. I therefore decided to operate on the spot, although the patient was a pauper and the surroundinga far from favour able. On the morning of the 3rd, chloroform having been. administered, I made an incision three inches long in the right. iliac region; the peritoneum was thick and vascular, and on dividing it I came upon a thickened mass which I took to be the edge of the great omentum. On separating the lower edge of this from its connexions about four ounces of foul-smelling fluid escaped; this was thin and semi-purulent. with flocculent material floating in it; no actual pus was found. The finger inserted into the wound failed to define clearly the appendix, it appeared to be curled up behind the cæcum; a mass of adherent small intestine could be felt at the upper and inner part of the cavity; the finger brought away two fæcal concretions of the size and shape of rice. grains, and four other similar concretions were subsequently found in the fluid that had been evacuated. The cavity was gently irrigated with warm mercuric chloride solution ( 1 in 2000), the upper part of the wound closed with a silkworm gut suture, and a rubber drainage-tube inserted. The patient rallied well from the operation, the pain was relieved, and there seemed at first every prospect of a quiet course. The temperature did not rise above $100^{\circ}$; the bowels, however, in. spite of enemata, were not opened, no flatus was passed, and. only a small lump of hard fæces, evidently from the lower 
bowel, the abdomen became increasingly distended, and by the evening of the $6 \mathrm{sh}$ this symptom had reached an alarming extent; during the night the patient became much worse and vomiting commenced. On the morning of the 7th the temperature was $97^{\circ}$ and the condition of the patient was very alarming, and it appeared to me that there was intestinal obstruction, probably from matting together of small intestine, and that it wonld be necessary to open the bowel for relief. About 11 A.M., however, a considerable uantity of flatus was passed with some relief to the distension and I decided to wait ; in about an hour a copious evacuation followed and all anxiety about obstruction was at an end. Except for the passage of residual contents of the large bowel, constipation had apparently been complete for ten days. During the afternoon of the same day (the 7th) a series of fits occurred, beginning with movements of the ingers of the right hand and gradually spreading to all the limbs, and followed by a period of complete unconsciousness lasting fully five minutes. During these attacks the head was turned strongly to the right and the eyeballs were tarned upwards. There was no optic neuritis. On the following morning the patient appeared to be a little better, though much exhausted, but complained that he was totally blind. The pupils were widely dilated. No change was discovered in the retinæ and there was no squint. A slight fit occurred about 4 P.M. The wound was looking well and suite sweet. Daring these two days there were frequent alvine evacuations, and in the course of the violent convulsions the dressings became disarranged and the wound soiled with frces. The distension of the abdomen was now completely relieved. On the night of the 8 th he had a long and refreshing sleep. The amaurosis had disappeared on the $9 \mathrm{th}$, and for several days afterwards the case ran an uneventful course. On the night of the 17th, however, the patient again complained of abdominal pain and his temperature went up to $101^{\circ}$. The wound had by this time much contracted and was looking well. The tube had been extruded on the 8th, and as there was very little discharge it had not been replaced. The temperature remained during the next two days at from $101^{\circ}$ to $102^{\circ}$ and the pain continued. On the 19th Mr. Ballance very kindly saw the patient and advised that a counter-opening should be made as far back as possible ; this step was carried out on the 20th and a drainage-tube was carried through; irrigation was practised from behind forwards. Some troublesome oozing took place. After the operation the temperature had fallen to $99^{\circ}$ and some considerable degree of improvement was manifested, but the patient's condition was not entirely satisfactory; there was considerable abdominal pain and the temperature did not reach the normal. On the 23rd, during irrigation, some clear fluid passed from the anus, but this did not again occur. On the 24th and 25th there was some hxmorrhage from the anterior wound and the temperature had gone up again to $102^{\circ}$. On the 27 th there had been no forther hæmorrhage, but the temperature remained high, the discharge was offensive, and the patient was evident]y suffering from septic absorption; the anterior wound was therefore dilated with the finger, some septic clot was removed, the cavity was well irrigated with hot perchloride lotion, and gauze packing was substituted for the drainage-tube. In the evening the temperature was $100^{\circ}$; there was no pain, and the general condition had already improved. The cavity was irrigated daily with hot chlorinated soda from behind forwards, and the plug in the anterior wound was changed daily. On the 30th a small slough separated, and on the 31st six large pieces of slough were washed away, wone of which could be recognised as being the appendjx. From this date convalescence was uninterrupted, and when dast seen (in Jane, 1896) the lad was in good health and had been in active work since the spring of 1894 . There was some tendency to hernia through the cicatrix. With the exception of the concretions found at the first operation no Excal matter had passed through the wound at any time.

Remarks.-This case in its protracted and stormy course, and in the extensive slougbing of false membranes that occurred, resembles that described by Mr. Stanmore Bishop in THE LANCET of Dec. 19th, 1896. I am at a loss to explain the convalsions that occurred-I suppose they were a toxic effect of the retained intestinal contents. I have, however, seen one such fit occar in a man daring the course of a mild attack of appendicitis. I was inclined to attribute the sloughing in my case to some secondary septic contamination the result of pauperism and dirty surroundings, but in Mr. Bishop's case, in which the lesions must have been very similar, there were no such influences. The developmen of a dangerous degree of abdominal distension af cer an apparently satisfactory operation was, I think, a remarkable feature in my case. I do not think Mr. Moynihan, in his article in THE LANCET of Dec. 26th, 1896, quite fairly represents the advice of Professor Reclus in regard to the operative treatment of these cases, for in the article on Appendicitis in the sixth volume of the "Traite de Chirurgie," edited by Reclus and Duplay, on p. 527 there occurs this passage: "Roux, ...... Dennis, Reclus, Berger, sont d'avis que trente-six ou quarante-huit heures d'aggravation progressive justifient pleinement l'intervention." One other curious phenomenon I met with in what I believe to have been an appendix case is, perhaps, worth relating. In the beginning of November, 1889, a man, aged thirty-four years, had abdominal pain and fever followed by well-marked exudation in the right iliac region; his symptoms were never acute, but in the second week, when the exudation was clearly subsiding, there developed emphysema over the right abdominal wall and the back of the right thigh; this persisted some three days and was not attended by any exacerbation of symptoms; no suppuration occurred. He made a good recovery without operation. I last saw him in the early part of 1896 and there had been then no recurrence. I think there must have been in this case a minute extra-peritoneal perforation.

Upper Edmonton.

\section{REMOVAL OF A BULLET FROM THE THIGH AFTER THREE YEARS BY THE AID OF X RAYS.}

\section{Br W.J. COLLINS, M.S., M.D., B.Sc. LoND., F.R.C.S. ENG. \\ SURGEON TO THE ROYAL EYE HOSPITAL AND THE LONDON TEMPERANCE HOSPITAL.}

A MAN, aged forty-three years, when leaving the train at Halifax, Nova Scotia, about three years ago, was shot at by a woman carrying a revolver. The woman was a stranger to him. At the trial a plea of insanity was set up, but failed, ands she is undergoing fourteen years' imprisonment. Examination at the time showed that a bullet had entered the right thigh between the great trochanter and the crest of the ilium. An attempt was made to extract it, but unsuccessfully. On Aug. 28th of this year he applied for

FIG. 1.

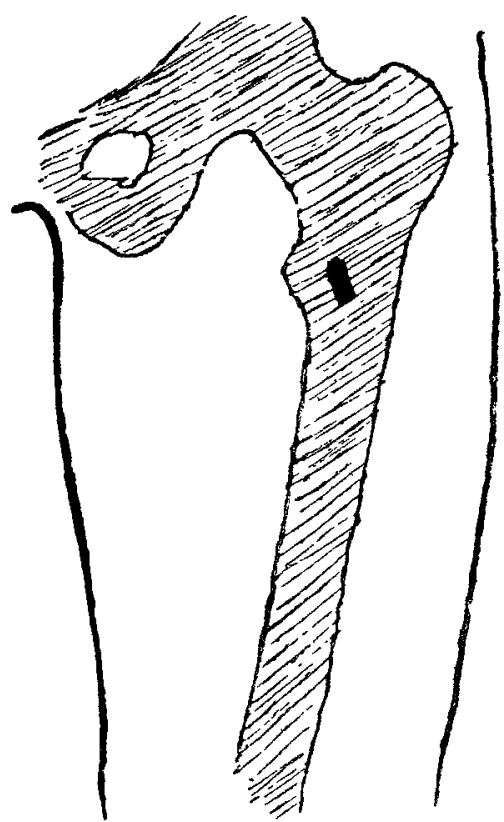

Fra. 2.

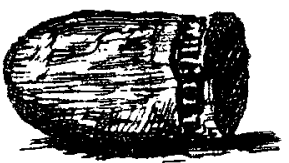

Facsimile of bullet.

Diagram showing position of bullet as seen in skiagraph.

admission under my care at the London Temperance Hospital. He was a healthy man; the cicatrix of the wound of entry was plainly visible about an inch above the right great trochanter. On the outer side of the right thigh, about midway between the great trochanter and the outer condyle, was a small abscess, evidently leading to a sinus. This had only appeared about a fortnight, and there was no 